Working

Paper

Department

of Economics

$\mathrm{Ca}^{\prime}$ Foscari University of

Venice

Roberto Roson

Equilibrium Size in Network with Indirect Network

Externalities: a Comment 


\title{
Equilibrium Size in Network with Indirect Network Externalities: a Comment
}

\author{
Roberto Roson \\ University of Venice
}

\section{Abstract}

This commentary critically reviews a recent paper by Baraldi (2004). It shows that results obtained there are not robust, and may mot hold after the introduction of minor changes in the model structure. It is claimed that this is not a technical point, but relates to the fundamental nature of markets with indirect externalities.

\section{Keywords}

Network Externalities, Two-Sided Markets.

\section{JEL Codes}

L10, L40.

\author{
Address for correspondence: \\ Roberto Roson \\ Department of Economics \\ Ca’ Foscari University of Venice \\ Cannaregio 873, Fondamenta S.Giobbe \\ 30121 Venezia - Italy \\ Phone: (++39) 0412349147 \\ Fax: (++39) 0412349176 \\ e-mail: roson@unive.it
}

This Working Paper is published under the auspices of the Department of Economics of the Ca' Foscari University of Venice. Opinions expressed herein are those of the authors and not those of the Department. The Working Paper series is designed to divulge preliminary or incomplete work, circulated to favour discussion and comments. Citation of this paper should consider its provisional character.

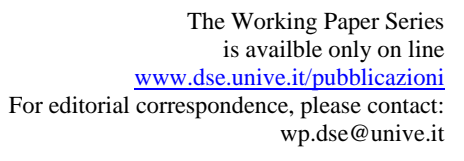

The Working Paper Series

Department of Economic

Ca' Foscari University of Venice

Cannaregio 873, Fondamenta San Giobbe

30121 Venice Italy

Fax: ++390412349210 


\section{Introduction}

In a recent paper, Baraldi (2004) introduces a model in which two market sides are linked by indirect network externalities. Equilibrium prices and network sizes are derived for a number of alternative market structures. It is found that the equilibrium size of the network(s) in perfect competition is always greater than the size in monopoly, for any value of the marginal cost and of the network externality parameter.

This result is not general, as it is strongly dependent on the (rather unrealistic) assumption of symmetry in network externalities. The reason why this outcome does not generally hold is not a minor technical point. It has to do with some key characteristics of markets with indirect network externalities, highlighted by several contributions in the rapidly growing literature on two-sided markets (Roson (2005)).

In this note, Baraldi's model is briefly summarized. An alternative model variant, and a counter-example, are subsequently introduced, to show that network size may actually be larger in monopoly than in perfect competition. A final section discusses why this may be the case, pointing out some interesting implications of market power and competition in two-sided markets.

\section{The Basic Model}

There are two symmetric markets $(i, j)$, in which consumers buy at most one unit of a good, whenever net utility turns out to be positive. The latter is expressed as:

$$
u_{i}=y_{i}-p_{i}+k n_{j}
$$

where $y$ (income) is a subjective parameter, uniformously distributed in $[0,1], p$ is the price of the good $i, k$ is a parameter (equal for both markets) and $n$ refer to the number of buyers in the opposite market $j$. The mass of consumers is normalized to 
one, so that $0 \leq n_{i}, n_{j} \leq 1$. It is shown that, for given prices:

$$
n_{i}=\frac{1-p_{i}+k\left(1-p_{j}\right)}{1-k^{2}}
$$

If prices are set by identical firms competing à la Bertrand, independently in the two markets, then $p_{i}=p_{j}=c$, if $c$ is a constant marginal cost, equal for all firms. In this case:

$$
n_{i}=\frac{1-c}{1-k}
$$

If prices are set by a profit-maximizing monopolist, jointly operating in the two markets, then it can be shown that:

$$
p_{i}=\frac{1+c}{2}
$$

and:

$$
n_{i}=\frac{1-c}{2(1-k)}
$$

meaning that network sizes in monopoly (5) are exactly half of those in perfect competition (3). This finding may look quite trivial; after all, prices are higher and quantities are lower in the presence of market power. This type of reasoning is wrong, however, in the context of two-sided markets, as it will be demonstrated in the following section.

Baraldi's paper continues by considering equilibria with independent (monopolistic) firms in the two markets, finding that complementarities bring about too high prices and too small networks, and the social optimum, in which network size exceeds the one of perfect competition, because of the existence of a sort of demand-side economies of scale. 


\section{A Model Variant and a Counter-Example}

Indirect network externalities are almost never symmetric in real markets. For example, consumers care about the number of merchants accepting credit cards, and merchants care about the number of credit card holders, but there is no reason to believe that these two effects are equally important. Actually, firms in two sided markets get most of their profits almost exclusively from one side only (Evans (2003)), whereas the other side often get the product for free (e.g., Adobe Reader software), or may be even subsidized.

Accordingly, let us replace (1) with:

$$
\begin{aligned}
& u_{1}=y_{1}-p_{1}+k n_{2} \\
& u_{2}=y_{2}-p_{2}+x n_{1}
\end{aligned}
$$

which, of course, includes Baraldi's model as a special case $(k=x)$. Following the same steps as in the original model, it can be easily shown that, in perfect competition:

$$
\begin{aligned}
& n_{1}=\frac{(1-c)(1+k)}{1-k x} \\
& n_{2}=\frac{(1-c)(1+x)}{1-k x}
\end{aligned}
$$

On the other hand, if a monopolist selects profit-maximizing prices, then:

$$
\begin{aligned}
& p_{1}=\frac{1-x+c(1-k)}{k+x-2} \\
& p_{2}=\frac{1-k+c(1-x)}{k+x-2}
\end{aligned}
$$

which implies:

$$
n_{1}=n_{2}=\frac{1-c}{2-k-x}
$$

Are network sizes as specified in (7) larger than in (9)? That depends on parameters' values, and it may not always be the case. 
To see this, suppose that $c=0.5, k=1.5, x=0$. This means that indirect network externalities work one-way: type- 1 consumers care about the number of type- 2 consumers, but not vice versa. In a perfect competition setting, $p=0.5, n_{1}=1.25, n_{2}=0.5$. Profits are zero, by construction. In the monopolistic case, $p_{1}=1.5, p_{2}=0$, so type-2 consumers pay nothing and are cross-subsidized by type- 1 consumers. Both network sizes are equal to 1 , and network in market 2 turns out to be larger in monopoly. Profit is 0.5 .

The interpretation is simple. Because the monopolist operates in both markets, she can internalize network externalities, by setting an appropriate price structure, balancing the two sides. She then choose not to charge type- 2 consumers, as an indirect mean of expanding the demand in the main market 1.

Furthermore, market integration always increase profits, and cases of firms operating independently in the two markets (as considered in most of Baraldi's paper) are not natural market configurations.

\section{Discussion}

Introducing competition, in markets affected by indirect network externalities, may generate unexpected results. Both a social planner and a two-sided "platform" (e.g. a credit card network) face the problem of "getting both sides on board". Rochet and Tirole (2004) make a useful distinction between exploitation of market power (choice of an aggregate price level) and the "balancing-act" (choice of a price structure for the sub-markets). A monopolistic platform balances the two market sides through an internalization of network externalities. This act is, in principle, in line with social welfare maximization.

The introduction of competition in a market, for example through the establishment of a duopoly in a formerly monopolistic market, generates two distinct effects: a reduction of market power held by the incumbent platform(s), and a change in the 
price structure. Relative prices may change because the competitive pressure may be stronger on one side. However, this translate into a "misalignment introduced by platform competition between the dominant platform's objectives and social welfare maximization" (Hagiu (2004)). Chakravorti and Roson (2004) show, nonetheless, that the effect of price reduction dominates the change in the price structure, with nonambiguous positive effects on welfare, unless market power of the incumbent platform was already restricted by the nature of the platform (e.g., non-profit, like in Rochet and Tirole (2002)), or by some other specific characteristics of the market (e.g., price regulation).

\section{References}

Baraldi, A.L (2004), "Equilibrium Size in Network with Indirect Network Externalities”, Rivista Italiana degli Economisti, vol. 9(3), pp. 475-494.

Chakravorti, S. and R. Roson (2004), "Platform Competition in Two-Sided Markets: The Case of Payment Networks". Federal Reserve Bank of Chicago Emerging Payments Occasional Paper Series, 2004-09.

Evans, D. (2003), “The Antitrust Economics of Multi-Sided Platform Markets”, Yale Journal on Regulation, vol. 20(2), pp. 325-382.

Hagiu, A. (2004), "Optimal Pricing and Commitment in Two-Sided Markets", in: Platforms, Pricing, Commitment and Variety in Two-Sided Markets, Ph.D. dissertation, Dept. of Economics, Princeton University.

Rochet, J.-C. and J. Tirole (2002), "Cooperation among Competitors: The Economics of Payment Card Associations", RAND Journal of Economics, vol. 33, pp. 549-570.

Rochet, J.-C. and J. Tirole (2004), “Two-Sided Markets: An Overview”, Mimeo, IDEI University of Toulouse. 
Roson, R. (2005), “Two-Sided Markets: a Tentative Survey”, Review of Network Economics, vol.4(2), pp. 142-160. 